\title{
Experimental Research on Spontaneous Combustion Tendency of High Volatile Blended Coals
}

\author{
Jinfeng Ma ${ }^{1}$, Fei Shao ${ }^{2}$, Junrui Shi ${ }^{1}$, Zhijia Xue ${ }^{1}$, Shuqun Wang ${ }^{1}$, Hongtao Li ${ }^{1}$, Huangxin Zhang ${ }^{1}$ \\ ${ }^{1}$ Department of Energy and Power, Shenyang Institute of Engineering, Shenyang, China \\ ${ }^{2}$ MI Ninth Design \& Research Institute Co., Ltd., Changchun, China \\ Email: majf69@yahoo.com.cn
}

Received August 18, 2012; revised January 25, 2013; accepted February 3, 2013

\begin{abstract}
Experiment of oxidation characteristics with slow velocity of high volatile blended coals was investigated in the surroundings of low oxygen conditions, which gives three kinetic factors in the step of low temperature through the methods of thermo gravimetric analysis, the Coats-Redfern integration and Achar-Brindley-Sharp-Wendworth. The results of calculation show that activation energy and pre-exponential factor increase with the reaction process, and tendency of spontaneous combustion of the blended coal have changed. The experimental results show that the type of absorbing oxygen is mainly physical adsorption and calorific value is very small during increasing weight. Volatile of blended coal releases before single coal and combustion temperature of blended coal is between one and other single coals. If the oxygen content is below $16 \%$ in the milling system, explosion-proof effect on high volatile blended coal can be obtained.
\end{abstract}

Keywords: Thermogravimetric Analysis; High Volatile; Blended Coal; Kinetic Theory; Oxidation Characteristics

\section{Introduction}

Adding inert medium in power station boiler system can reduce the oxygen concentration and realize the inhibition of combustion reaction. It can also eliminate the pulverized coal spontaneous combustion and ignition source. In a word, it is a very effective method of preventing explosion. Referring to high volatile pulverized coal explosion-proof standards of other countries, China regulates that explosion protection index of oxygen volume share is less than $14 \%$. Considering the drying requirements of lignite, bituminous coal boiler burning with lignite is difficult to meet explosion index above, so research on oxidation characteristics of high volatile blended coal in the surroundings of low oxygen atmosphere is carried on in this paper.

Long-term accumulation of coal powder in powder system after slow oxidation may be spontaneous ignition. Many domestic scholars have studied coal oxidation and pyrolysis characteristics. Aiming at the particle size with $150 \mu \mathrm{m}$ and oxygen concentration with $21 \%$, research of coal oxidation spontaneous combustion begins, which is carried on in reference [1-3]. Coal powder of $20-60 \mu \mathrm{m}$ in the powder plant boiler is in the majority, reference [4-8] studies about only the pulverized coal under the inert condition of pyrolysis, the combustion characteristics and burnout characteristics under the condition of high temperature and oxidation on the particle size range of coal powder, while slow oxidation spontaneous combustion characteristics of blended coal under the condition of low temperature and low oxygen are not in-depth study.

Aiming at high volatile Huolinhe lignite and three kinds of typical northeast bituminous coal preparation of mixed coal, according to high volatile coal explosionproof technology index at home and abroad $[9,10]$, the application of thermal analysis technology develops slow oxidation experiment in the surroundings of low oxygen atmosphere with $12 \%, 14 \%$ and $16 \%$ oxygen and dynamic analysis, and it is concluded that oxidation characteristics parameters of coal and dynamic parameters of characterization of pulverized coal self-ignition orientation, that is for slow oxidation experiment research in oxygen atmosphere, providing theoretical basis for explosion-proof design and operation of bituminous coal boiler burning with lignite.

\section{Experimental Part}

The experiment is conducting in the SMP/PF7548/MET/ $600 \mathrm{~W}$ thermal analysis instrument from Swiss METTLER TOLEDO-United States (China) Company. Before pulverized coal in the coal preparation System go into the boiler, the oxidation and pyrogenation process of 
the accumulated powder belongs to slow oxidation pyrogenation process. In order to achieve coal oxidation exothermic information, experiment carried on variable heating rate with heating slowly in low temperature, and heating fast in high temperature [3]. $25^{\circ} \mathrm{C}-200^{\circ} \mathrm{C}$ at heating rate of $2^{\circ} \mathrm{C} \cdot \mathrm{min}^{-1}$ and $200^{\circ} \mathrm{C}-650^{\circ} \mathrm{C}$ at heating rate of $10^{\circ} \mathrm{C} \cdot \mathrm{min}^{-1}$ were selected, the oxygen concentration was $12 \%, 14 \%$ and $16 \%$ in the experiment. Coal samples are from Huolinhe lignite (HLH), Fuxin bituminous coal (FX), Fushun bituminous coal (FSH) and Tiefa bituminous coal (TF). The average particle size is $53 \mu \mathrm{m}$. The results of coal quality analysis are in Table 1. The number and composition of blended coal are in Table 2 .

\section{The Experiment Results and Analysis}

The trends of Thermogravimetric analysis (TG), Differential thermogravimetric analysis (DTG) and Differential scanning calorimetry (DSC) curves are same. The chart 1 is an example of blended coal which gives experimental results of heat analysis in 16\% oxygen concentration from Figure 1. Figure 2 shows variation diagram of coal oxidation characteristic parameters with the change of oxygen concentration.

According to the references $[11,12]$, coal oxidation process are divided into 5 stages, that are water evaporation and desorption weightlessness stage (initial temperature $\left.\sim T_{1}\right)$; oxygen absorption and weight gain $\left(T_{1}-T_{s}\right)$; thermal decomposition $\left(T_{s}-T_{i}\right)$; combustion $\left(T_{i}-T_{2}\right)$ and burnout $\left(T>T_{2}\right)$; in which $T_{1}$ is the completion of water evaporation and desorption temperature; $T_{s}$ is volatiliza- tion separating temperature; $T_{i}$ is ignition temperature; $T_{2}$ is the corresponding temperature of complete combustion. The experiment studies low temperature oxidation of coal, so the 3 stages are not considered after the step.

From the Figure 1, in the step of water evaporation and desorption, the environment temperature is quite low and coal oxygen molecules between the collision and contact in the slow condition and activated molecules in coal are very few. Reaction rate between coal and oxygen is very slow. Damage of the original key coal and new material production become quite difficult. Moisture and inherent moisture of coal have been evaporated, also gas absorption in coal is desorption. Coal sample is absorbed in oxygen when water evaporats, owing to water evaporation loss weight is greater than the oxygen gain weight, TG curves showed a downward trend. DSC curve is negative, and the stage of coal sample is in the absorbing state.

In the step of oxygen absorption and weight increasing, temperature of pulverized coal increases and the chance of binding collisions between oxygen and coal increases and activated molecule increases and chemical reaction speeds up. Because of water evaporation and desorption, the pulverized coal porosity and free surface increase, and pulverized coal is absorbed in oxygen fast, TG curve is a tendency of rising. If chemical oxygen and chemical reaction of oxygen consumption are mainly in the stage, heat will increase, DSC curves rises with oxidation temperature rising. But in Figure 1, DSC curve drops first with the increase of temperature, DSC curve showed a

Table 1. The analysis results of coal samples.

\begin{tabular}{cccccccccc}
\hline \multirow{2}{*}{ Coal samples } & \multicolumn{4}{c}{ Element analysis (\%) } & \multicolumn{5}{c}{ Industrial analysis (\%) } \\
\cline { 2 - 10 } & $\mathrm{C}_{\mathrm{ar}}$ & $\mathrm{H}_{\mathrm{ar}}$ & $\mathrm{O}_{\mathrm{ar}}$ & $\mathrm{N}_{\mathrm{ar}}$ & $\mathrm{S}_{\mathrm{ar}}$ & $\mathrm{M}_{\mathrm{ad}}$ & $\mathrm{A}_{\mathrm{ad}}$ & $\mathrm{V}_{\mathrm{ad}}$ & $\mathrm{F}_{\mathrm{ad}}$ \\
\hline $\mathrm{HLH}$ & 37.73 & 2.64 & 10.37 & 0.64 & 0.31 & 7.28 & 21.93 & 34.32 & 36.47 \\
$\mathrm{FSH}$ & 38.11 & 2.39 & 9.51 & 0.73 & 0.3 & 1.69 & 31.50 & 34.50 & 32.31 \\
$\mathrm{FX}$ & 42.71 & 2.72 & 8.77 & 0.5 & 0.9 & 5.99 & 24.49 & 30.00 & 39.52 \\
$\mathrm{TF}$ & 42.24 & 2.61 & 10.0 & 0.61 & 0.39 & 3.95 & 33.80 & 27.52 & 34.73 \\
\hline
\end{tabular}

Table 2. Composition and tag of blended coals.

\begin{tabular}{ccccc}
\hline Blended coal number & HLH & FSH & TF & FX \\
\hline $1^{\#}$ & $70 \%$ & $30 \%$ & 0 & 0 \\
$2^{\#}$ & $50 \%$ & $50 \%$ & 0 & 0 \\
$3^{\#}$ & $70 \%$ & 0 & 0 & $30 \%$ \\
$4^{\#}$ & $50 \%$ & 0 & 0 & $50 \%$ \\
$5^{\#}$ & $70 \%$ & 0 & $30 \%$ & 0 \\
$6^{\#}$ & $50 \%$ & 0 & $50 \%$ & 0 \\
\hline
\end{tabular}



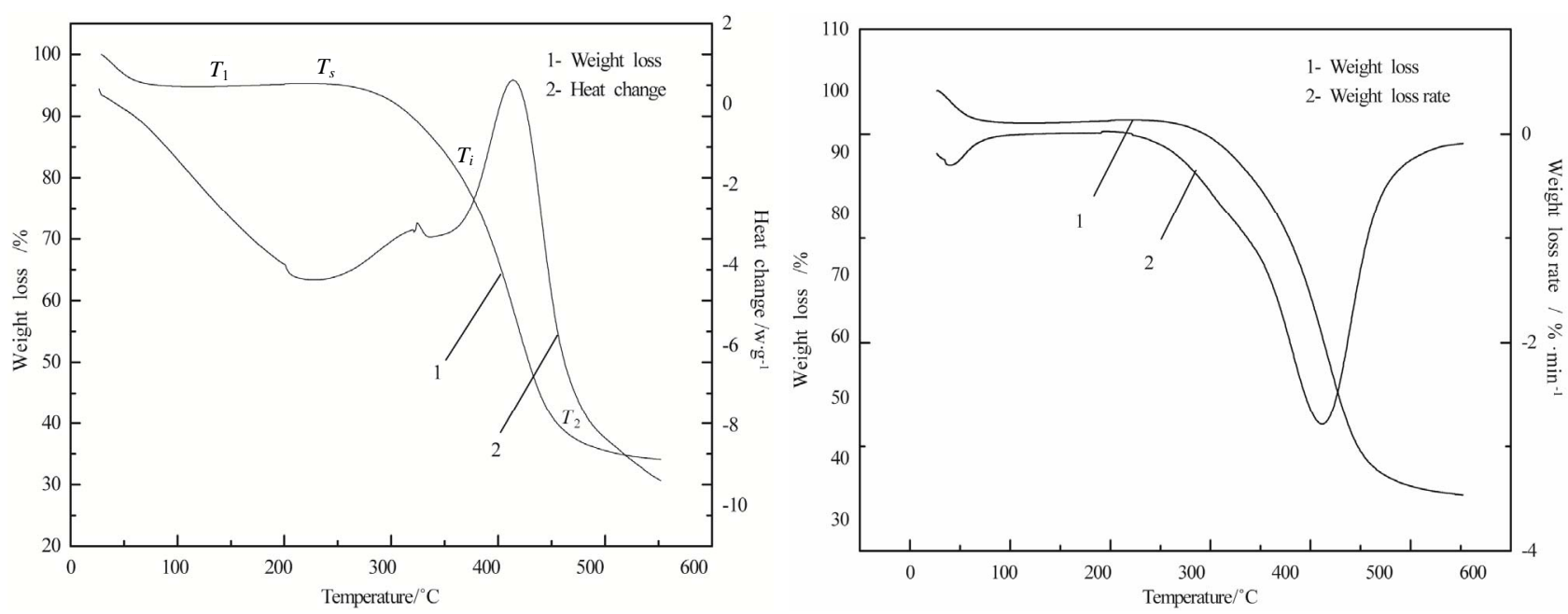

Figure 1. Thermal analysis curves of coal sample.

rising trend nearly at the end of oxygen increasing weigh. It explains that the coal oxygen is mainly physical adsorption, and oxidation heat of chemical adsorption and reaction are little, indicating in pulverizing system in less than $16 \%$ oxygen concentration can achieve an explosion effect of high volatile blended coal.

Combustion and explosion of essence of pulverized coal are mixed with oxygen that forms explosion, volatilization separating temperature $T_{\mathrm{s}}$ has an important influence on spontaneous combustion and explosion of coal. From Figure 2, with the oxygen concentration increasing, variation of coal volatilization separating temperature is inconsistent, this is because volatile devolatilization connects with the atmosphere condition under oxidizing conditions, and it is mainly relation to coal sample's microstructure. Volatile devolatilization temperature of blended coal basically is lower than the corresponding single coal, concluding that blended coal volatile in advance compared with single coal.

Coal spontaneous combustion is the ignition temperature. This paper uses the commonly method of TG-DTG to determine temperature of the pulverized coal ignition [12]. From the Figure 2, the ignition temperature decreases with the oxygen concentration increasing. Ignition temperature of blended coal is between one and other corresponding single coals. With the proportion of Huolinhe lignite increasing, ignition temperature of mixed coal decreases. Compared with $14 \%$ oxygen concentration, volatilization separating temperature and ignition temperature lower values of coal samples are below $9^{\circ} \mathrm{C}$ on the condition of $16 \%$ oxygen concentration.

\section{Calculation of Kinetic Parameters}

\subsection{Dynamic Analysis Method}

This paper uses Coats-Redfern integration and Achar-
Brindley-Sharp-Wendwort differential methods and makes use of 18 kinds of kinetic mechanism function relying on reference [13]. Compared with the calculation results of the same mechanism function of differential method and integral method, the mechanisms of the reaction functions are inferred by Bagchi [14].

According to the law of mass action and Arrhenius equation

$$
\frac{\mathrm{d} \alpha}{\mathrm{d} t}=A \exp (-E / R T) f(\alpha)
$$

Using non-isothermal method, increasing temperature with constant heating rate, and setting up the heating rate $\beta=\frac{\mathrm{d} T}{\mathrm{~d} t}$, Equation (1) can be transformed into

$$
\frac{\mathrm{d} \alpha}{f(\alpha)}=\frac{A}{\beta} \exp (-E / R T) \mathrm{d} T
$$

Definition

$$
G(\alpha)=\int_{0}^{\alpha} \frac{\mathrm{d} \alpha}{f(\alpha)}
$$

Coats and Redfern, according to Equations (1)-(3), that are derived and simplified to Coats-Redfern integral French program is as follow,

$$
\ln \left[\frac{G(\alpha)}{T^{2}}\right]=\ln \left[\frac{A R}{\beta E}\right]-\frac{E}{R T}
$$

Equation (1) is for separation of variables, on both sides of the exponential Achar-Brindley-Sharp-Wendworth differencial French programs is as follow,

$$
\ln \left[\frac{\mathrm{d} \alpha / \mathrm{d} t}{f(\alpha)}\right]=\ln A-\frac{E}{R T}
$$

where, $\alpha$ is conversion rate of reaction; $t$ is reaction 

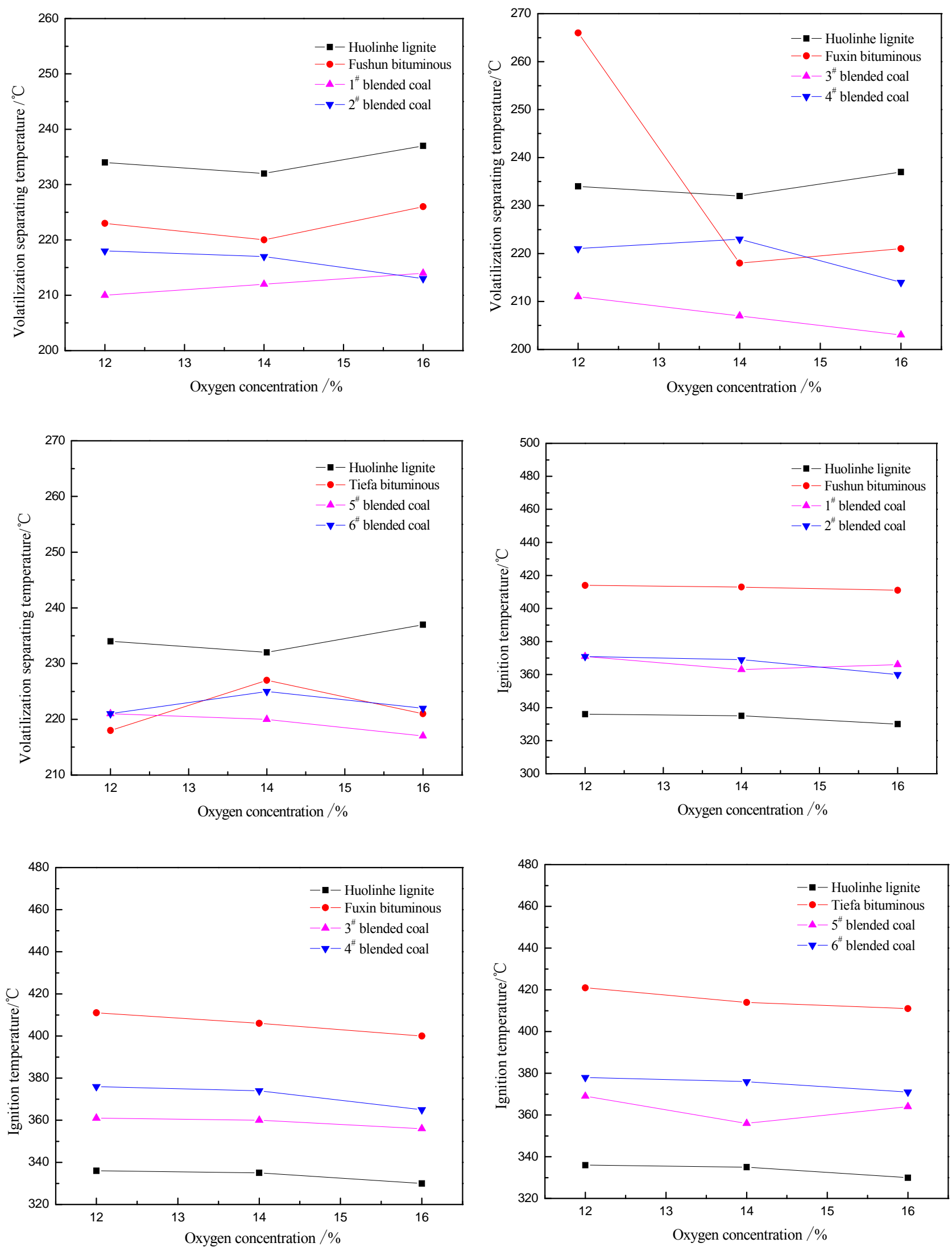

Figure 2. Oxidation characteristics parameters with different oxygen concentration. 
time, $\min ; T$ is thermodynamic temperature, $\mathrm{K} ; A$ is apparent pre-exponential factor, $\min ^{-1} ; E$ is apparent activation energy, $\mathrm{J} / \mathrm{mol} ; R$ is molar gas constant, its value is $8.31 \mathrm{~J} \cdot \mathrm{K}^{-1} \cdot \mathrm{mol}^{-1} ; f(\alpha)$ and $G(\alpha)$ are respectively for the reaction mechanism of differential form and integral form.

\subsection{The Calculation Results}

Apparent pre-exponential factor is parameters of the combustion reaction speed. The greater the pre-exponential factor, the more intense reaction speed is showed. The apparent activation energy is on behalf of the reactant molecules from the initial steady state, which becomes activated molecules required for absorption of minimum energy. Their numerical size reflects the response of difficulty level [15]. Usually the smaller the activation energy is, the less spontaneous combustion tendency, the possibility of explosion reduces. The reference [16] makes the activation energy in low temperature oxidation stage from $45^{\circ} \mathrm{C}$ to $70^{\circ} \mathrm{C}$ as spontaneous combustion tendency identification indexes of coal. The reference [11] says after the loss of water, coal adsorbed plenty of oxygen when generating complex physical and chemical reaction in weight gain stage. The phase of the activation energy is intrinsically connected with the chemical structure and coal spontaneous combustion mechanism of coal, which expresses difficulty level of normal temperature oxidation and spontaneous combustion of coal accurately.

On the basis of this paper, according to the thermal analysis of experimental results in $16 \%$ oxygen concentration, in view of water evaporation and desorption and oxygen gain stage, conducting kinetic parameters calculation, the results in Table 3. To obtain kinetic mecha- nism function of high volatile mixed coal.

Reaction mechanism function is reaction model of $n=$ 3 in water evaporation and desorption stage.

where

$$
\begin{gathered}
f(\alpha)=(1-\alpha)^{3} \\
G(\alpha)=\frac{1}{2}\left[(1-\alpha)^{-2}-1\right]
\end{gathered}
$$

Reaction mechanism function is reaction model of $n=$ $3 A-E$ in oxygen absorption and weight gain stage.

where,

$$
\begin{aligned}
& f(\alpha)=\frac{1}{3}(1-\alpha)[-\ln (1-\alpha)]^{-2} \\
& G(\alpha)=[-\ln (1-\alpha)]^{-2}
\end{aligned}
$$

The calculation results are in Table $\mathbf{3}$, the activation energy and pre-exponential factor of Huolinhe lignite increase when the reaction process is in depth, the activation energy and pre-exponential factor of three kinds of bituminous coal decrease when the reaction process is in depth.

In water evaporation and desorption stage,

$$
\begin{aligned}
& E_{\mathrm{HLH}}<E_{\mathrm{TF}}<E_{\mathrm{FX}}<E_{\mathrm{FSH}}, \\
& \ln A_{\mathrm{HLH}}<\ln A_{\mathrm{TF}}<\ln A_{\mathrm{FX}}<\ln A_{\mathrm{FSH}},
\end{aligned}
$$

namely the sort law of the activation energy and preexponential factor are the same. But, the activation energy of Huolinhe lignite is obviously lower than three

\begin{tabular}{|c|c|c|c|c|c|c|c|c|}
\hline \multirow{2}{*}{ Coal samples } & \multicolumn{4}{|c|}{ Water evaporation and desorption stage } & \multicolumn{4}{|c|}{ Oxygen absorption and weight gain stage } \\
\hline & Temperature range $/{ }^{\circ} \mathrm{C}$ & $E / \mathrm{kJ} \cdot \mathrm{mol}^{-1}$ & $\ln A / \min ^{-1}$ & $r$ & Temperature range $/{ }^{\circ} \mathrm{C}$ & $E / \mathrm{kJ}^{\prime} \cdot \mathrm{mol}^{-1}$ & $\ln A / \min ^{-1}$ & $r$ \\
\hline HLH & $25-123.23$ & 161.36 & 58.42 & 0.9854 & $123.23-220.99$ & 263.30 & 64.90 & 0.9767 \\
\hline FSH & $25-69.06$ & 273.09 & 100.63 & 0.9584 & $69.06-283.50$ & 119.04 & 26.18 & 0.9789 \\
\hline $\mathrm{FX}$ & $25-80.29$ & 250.59 & 94.08 & 0.9787 & $80.29-279.50$ & 162.05 & 38.05 & 0.9847 \\
\hline $\mathrm{TF}$ & $25-81.79$ & 237.43 & 88.53 & 0.9855 & $81.79-285.15$ & 149.28 & 34.37 & 0.9820 \\
\hline $1^{\#}$ & $25-157.67$ & 87.14 & 32.27 & 0.9825 & $157.67-237.86$ & 357.96 & 89.92 & 0.9456 \\
\hline $2^{\#}$ & $25-95.51$ & 196.92 & 71.66 & 0.9695 & $95.51-252.18$ & 208.68 & 50.49 & 0.9599 \\
\hline $3^{\#}$ & $25-116.11$ & 163.48 & 58.62 & 0.9880 & $116.11-228.33$ & 286.32 & 69.92 & 0.9558 \\
\hline $4^{\#}$ & $25-167.06$ & 63.18 & 25.76 & 0.9870 & $167.06-238.81$ & 527.65 & 159.65 & 0.9821 \\
\hline $5^{\#}$ & $25-104.33$ & 183.84 & 66.86 & 0.9857 & $104.33-242.33$ & 231.75 & 56.50 & 0.9538 \\
\hline $6^{\#}$ & $25-96.85$ & 213.96 & 78.26 & 0.9599 & $96.85-256.03$ & 201.50 & 48.57 & 0.9714 \\
\hline
\end{tabular}
kinds of bituminous coal. According to the view of reference [16], spontaneous combustion tendency of Huolinhe lignite is the largest. The activation energy $E$ and pre-exponential factor $A$ sort law of blended coal are as

Table 3. Results of kinetics parameters. 
follows:

$$
\begin{aligned}
& E_{1}^{\#}<E_{\mathrm{HLH}}<E_{2}^{\#}<E_{\mathrm{Fushun}}, E_{4}^{\#}<E_{\mathrm{HLH}}<E_{3}^{\#}<E_{\mathrm{FX}}, \\
& E_{\mathrm{HLH}}<E_{5}^{\#}<E_{6}^{\#}<E_{\mathrm{TF}}<\ln A_{1}^{\#}<\ln A_{\mathrm{HLH}}<\ln A_{2}^{\#}<\ln A_{\mathrm{FSH}}, \\
& \ln A_{4}^{\#}<\ln A_{\mathrm{HLH}}<\ln A_{3}^{\#}<\ln A_{\mathrm{FX}}, \\
& \ln A_{\mathrm{HLH}}<\ln A_{5}^{\#}<\ln A_{6}^{\#}<\ln A_{\mathrm{TF}} .
\end{aligned}
$$

Compared with bituminous coal, the activation energy of blended coal burning that is composed of Fushun bituminous coal, Fuxin bituminous coal with Huolinhe lignite reduces, according to the view of reference [16], spontaneous combustion tendency of high volatile blended coal increases.

In oxygen absorption and weight gain stage, the activation energy of Huolinhe lignite is obviously higher than three kinds of bituminous coal, sort law of pre-exponential factor is the same, namely

$$
\begin{aligned}
& E_{\mathrm{FSH}}<E_{\mathrm{TF}}<E_{\mathrm{FX}}<E_{\mathrm{HLH}}, \\
& \ln A_{\mathrm{FSH}}<\ln A_{\mathrm{TF}}<\ln A_{\mathrm{FX}}<\ln A_{\mathrm{HLH}} .
\end{aligned}
$$

According to the view of reference [11], spontaneous combustion tendency of Fushun bituminous coal is the largest. The activation energy $E$ and pre-exponential factor $A$ sort law of blended coal are as follows:

$$
\begin{aligned}
& E_{\mathrm{FSH}}<E_{2}^{\#}<E_{\mathrm{HLH}}<E_{1}^{\#}, \\
& E_{\mathrm{FX}}<E_{\mathrm{HLH}}<E_{3}^{\#}<E_{4}^{\#}, \\
& E_{\mathrm{TF}}<E_{6}^{\#}<E_{5}^{\#}<E_{\mathrm{HLH}}, \\
& \ln A_{\mathrm{FSH}}<\ln A_{2}^{\#}<\ln A_{\mathrm{HLH}}<\ln A_{1}^{\#}, \\
& \ln A_{\mathrm{FX}}<\ln A_{\mathrm{HLH}}<\ln A_{3}^{\#}<\ln A_{4}^{\#}, \\
& \ln A_{\mathrm{TF}}<\ln A_{6}^{\#}<\ln A_{5}^{\#}<\ln A_{\mathrm{HLH}},
\end{aligned}
$$

the activation energy of blended coal is higher than the corresponding bituminous coal, according to the view of reference [11], spontaneous combustion tendency of high volatile mixed coal reduces.

\section{Conclusions}

1) The experimental results show that oxygen inhalation of high volatile coal in the surroundings of $16 \%$ oxygen atmosphere is mainly physical adsorption, and the heat of chemical adsorption and oxidation are few. Volatile of blended coal release before single coal, and ignition temperature is between one and other coals; compared with $14 \%$ oxygen concentration, oxidation characteristics temperature of blended coal has little change in the condition of $16 \%$ oxygen concentration. If the oxygen content of the coal pulverizing system is $16 \%$, it can achieve an explosion proof effect of blended coal and a certain reference value for engineering application of bituminous coal boiler burning with lignite.

2) High volatile pulverized coal in boiler operation of the primary air temperature is within the interval of water evaporation and desorption. The results show that activation energy of Huolinhe lignite is minimum and selfignition orientation is maximum in the stage, according with the law of easy to burning to high volatile coal, compared with bituminous coal. The activation energy of high volatile blended coal decreases, but tendency of spontaneous combustion increases in the stage. People should pay attention to monitoring and control oxygen concentration of pulverized coal system in the actual operation of burning with lignite in bituminous coal boiler.

\section{REFERENCES}

[1] M. Yu, Y. Zheng and C. Lu, "Thermal Analysis Experiment on Low-Temperature Oxidation and Pyrolysis of Coal," China Safety Science Journal, Vol. 19, No. 9, 2009, pp. 83-86.

[2] M. G. Yu, Y. M. Zheng and C. Lu, "Kinetic Analysis of Oxidation and Degradation Reaction of Lignite and Lean Coal," Fire Safety Science, Vol. 18, No. 3, 2009, pp. 143146.

[3] Q. L. He and D. M. Wang, "Kinetics of Oxidation and Thermal Degredation Reaction of Coal," Journal of Science and Technology Beijing, Vol. 28, No. 1, 2006, pp. 14.

[4] L. H. Wei, R. D. Li and A. M. Li, "Thermogravimetric Analysis on the Pyrolysis Characteristics of Pulverized Coal," Proceedings of the Chinese Society for Electrical Engineering, Vol. 28, No. 26, 2008, pp. 53-58.

[5] X. Gou, "Experimental, Theoretical and Numerical Simulation Research on Direct Flow Pulverized Coal Low $\mathrm{NO}_{x}$ Combustion and Reburning Technology," Ph.D. Thesis, Zhejiang University, Hangzhou, 2007.

[6] X. H. Xian, Y. G. Du and G. H. Zhang, "Combusion Characteristics of Coal Blending by TG-DTG/DTA," Coal Conversion, Vol. 34, No. 5, 2011, pp. 67-70.

[7] Q. Tang, L. P. Wang and Y. F. Yan, "Study on Combusion and Kinetic Characteristics of Pulverized Coalin Oxygen Enriched Environments," Coal Conversion, Vol. 32, No. 3, 2009, pp. 55-59.

[8] L. H. Wei, "Study on Combusion Mechanism of MicroPulverized Coal," Harbin Institute of Technology, Harbin, 2007.

[9] L. Guan, "Study on Explosion Venting of Coal Pulverizing Process in Power Plant," Northeastern University, Shenyang, 2003.

[10] J. F. Ma, J. X. Wu and T. S. Zhou, "Study on Lignite Blended Burning Technology in the Bin Feedercoal Pulverizing System," Journal of Power Engineering, Vol. 28, No. 1, 2008, pp. 14-18.

[11] C. B. Deng, "Study on Coal Spontaneous Combustion Mechanisms and Spontaneous Combustion Danger In- 
dex," Liaoning Technical University, Fuxin, 2006.

[12] X. Y. Ge, "Experimental Research on Oxidation Kinetics of Coal Based on Thermal Analysis Technology," Anhui University of Science and Technology, Huainan, 2009.

[13] R. Z. Hu and Q. Z. Shi, "Kinetics of Thermal Analysis," Science Press, Beijing, 2001.

[14] T. P. Bagchi, P. K. Agarwal and R. D. Gunn, "Calculation of Thermal Explosion Limits," Thermochimca Acta,
No. 51, 1981, pp. 175-176. doi:10.1016/0040-6031(81)85157-X

[15] Y. Z. Li, "Thermal Analysis," Tsinghua University Press, Beijing, 1987.

[16] W. Lu, D. M. Wang and X. X. Zhong, "Tendency of Spontaneous Combustion of Coal Based on Activation Energy," Journal of China University of Mining and Technology, Vol. 35, No. 2, 2006, pp. 201-205. 